\title{
Redundant expression of canonical Wnt ligands in human breast cancer cell lines
}

\author{
KHEMAIS BENHAJ, KAMIL CAN AKCALI and MEHMET OZTURK
}

\author{
Department of Molecular Biology and Genetics, Bilkent University, 06800 Ankara, Turkey
}

Received August 4, 2005; Accepted September 15, 2005

\begin{abstract}
Human breast cancer displays nuclear accumulation of $\beta$-catenin and induction of cyclin D1 expression, which suggests that canonical Wnt/ß-catenin signaling is activated. In other cancers, the activation of canonical wnt/B-catenin signaling is associated with $A P C, C T N N B 1$ or $A X I N 1$ mutations. However, these mutations are rare or absent in breast cancer. In search of alternative mechanisms, we performed comprehensive expression analysis of Wnt signaling molecules, including 19 Wnt ligands, ten Frizzled receptors, two co-receptors and four Lef/TCF transcription factors in immortalized normal human mammary epithelial cells (HMEC) and six breast cancer cell lines. HMEC expressed all Frizzled receptors except FZD 9 and FZD10. They also expressed LRP5 and $L R P 6$ co-receptors, as well as four Lef/TCF transcription factors. HMEC cells also expressed many Wnt ligands, including WNT1, WNT2B, WNT3, WNT5A, WNT5B, WNT7B, WNT9A, WNT10B and WNT16. Redundant expression of Wnt ligands, Frizzled receptors, co-receptors and Lef/TCF transcription factors was maintained in breast cancer cell lines with some exceptions. The most important changes in cancer cell lines concerned Wnt ligand expression. We noticed that most breast cancer cell lines overexpressed $W N T 3 A$, WNT4, WNT6, WNT8B, WNT9A and WNT10B. In contrast, the expression of WNT5A, WNT5B and WNT16 was usually down-regulated. It is noteworthy that all six Wnt ligands that are overexpressed in malignant cell lines are known to signal through the canonical Wnt/ß-catenin signaling pathway, whereas down-regulated WNT5A and WNT5B ligands signal via the non-canonical pathway. The expression of both canonical Wnt ligands and most Frizzled receptors in breast cancer cell lines suggests that canonical Wnt/ß-catenin signaling is activated in these cell lines by an autocrine/ paracrine mechanism. In support of this prediction, we observed nuclear $\beta$-catenin accumulation and cyclin D1 induction in breast cancer cell lines, but not in HMEC. These
\end{abstract}

Correspondence to: Dr Mehmet Ozturk, Department of Molecular Biology and Genetics, Bilkent University, 06800 Ankara, Turkey

E-mail: ozturk@fen.bilkent.edu.tr

Key words: Wnt, Frizzled, breast cancer, mammary epithelial cell line, B-catenin, cyclin D1 results imply that ligand-dependent canonical Wnt/ß-catenin signaling is active in human breast cancer.

\section{Introduction}

Wnt signaling, initially identified in the early embryogenesis of Drosophila, is involved in a large set of cellular processes, including proliferation, differentiation, migration, and apoptosis $(1,2)$. It includes three different pathways; namely the canonical $\mathrm{Wnt} / \mathrm{ß}$-catenin pathway, and non-canonical $\mathrm{Wnt} / \mathrm{Ca}^{++}$and Wnt/planar cell polarity pathways (3-5). Canonical Wnt signaling is involved in cell fate choices and stem-cell renewal and differentiation, whereas non-canonical signaling deals with morphological changes and tissue organization $(3,5,6)$. Aberrant activation of the $\mathrm{Wnt} / \mathrm{B}$-catenin signaling pathway is one of the most frequent abnormalities in human cancer. In colorectal cancer, canonical Wnt signaling is aberrantly activated by mutations affecting either the $A P C$ tumor suppressor gene $(85 \%)$ or $\beta$-catenin-encoding CTNNB 1 oncogene $(10 \%)(6)$. In liver cancer, frequent accumulation of $\beta$-catenin protein correlated with CTNNB1 and AXIN1 mutations (6), and p53 mutations (7).

Since the discovery of Wnt- 1 as a mouse mammary tumor virus-induced oncogene in mouse breast tumors, Wnt signaling has become a center of interest in human breast carcinogenesis. Surprisingly, however, human breast cancers do not display genetic alterations in the known mutational target genes of Wnt signaling, including APC, CTNNB1 and AXIN1 (6,8-11). On the other hand, cyclin D1, a well-known transcriptional target of canonical Wnt signaling is overexpressed in primary breast tumors (12). In the absence of related mutations, the molecular mechanisms of aberrant B-catenin and cyclin D1 expression in human breast cancer remains poorly known.

In this report, we undertook a systematic study of the expression of all major components of Wnt signaling in human breast cancer cell lines. Using the RT-PCR technique, we analyzed the expression profiles of 19 known Wnt ligands, 10 known Frizzled receptors, two LRP co-receptors and four Lef/TCF transcription factor genes, in a panel of six breast cancer cell lines. Telomerase-immortalized normal human mammary epithelial cell line, hTERT-HME1 (HMEC), was used as normal control. We also analyzed nuclear $\beta$-catenin protein, and cyclin D1 and c-myc transcripts in these cells. Here, we provide evidence that normal and malignant breast epithelial cells display redundant expression of ligands, receptors, co-receptors and transcription factors involved in both canonical and non-canonical Wnt signaling. Our results 
indicate that the expression of canonical Wnt ligands was up-regulated, whereas non-canonical WNT5A and WNT5B expression was down-regulated in breast cancer cell lines. These changes in Wnt ligand expression were correlated with the accumulation of nuclear $ß$-catenin and induction of cyclin D1 expression in breast cancer cell lines, strongly suggesting that human breast malignancy is associated with liganddependent activation of the canonical Wnt/ß-catenin signaling.

\section{Materials and methods}

Cell lines. Breast cancer cell lines (MCF-7, T47-D, BT-474, BT-20, MDA-MB-453, MDA-MB-468; all from ATCC), telomerase-immortalized human mammalian epithelial cell line hTERT-HME1 (HMEC; Clontech) and hepatocellular carcinoma cell lines, Hep40 and SNU182 (13), were used in this study. With the exception of HMEC, all cell lines were grown in Dulbecco's modified Eagle's medium (DMEM) supplemented with $10 \%$ FCS and $50 \mathrm{mg} / \mathrm{ml}$ penicillinstreptomycin. hTERT-HME1 (HMEC) cells were cultivated in DMEM/Ham's F12 (Biochrom) containing insulin (3.5 $\mu \mathrm{g}$ / $\mathrm{ml})$, EGF $(0.1 \mathrm{ng} / \mathrm{ml})$, hydrocortisone $(0.5 \mu \mathrm{g} / \mathrm{ml}), 10 \% \mathrm{FBS}$ (Biochrom), and $50 \mathrm{mg} / \mathrm{ml}$ penicillin-streptomycin.

RNA extraction and cDNA synthesis. Total RNAs were isolated from cultured cells using the NucleoSpin RNA II Kit (MN Macherey-Nagel, Duren, Germany) according to the manufacturer's protocol. The cDNAs were synthesized from $2 \mu \mathrm{g}$ of total RNA as a template, using RevertAid First Strand cDNA synthesis kit (MBI Fermentas, Vilnius, Lithuania). A negative control without reverse transcriptase $(1 \mu \mathrm{lddH} 2 \mathrm{O}$ instead) was also prepared for each sample.

RT-PCR and multiplex RT-PCR. The list of primers used for these analyses is provided in Table I. The PCR reactions were usually carried out with $1 \mu \mathrm{l} \mathrm{cDNA}$, using the appropriate number of cycles and annealing temperature $(\mathrm{Tm})$ provided in Table I. Negative controls without reverse transcriptase were included for each set of primers. Multiplex RT-PCR reactions were carried out using $8 \mathrm{pmol} / \mu 1$ of cyclin D1 or cmyc primers along with $2 \mathrm{pmol} / \mu 1$ of GAPDH primers for a total cycle number of 30 and 35 for cyclin D1 and c-myc, respectively. PCR products were analyzed on a $2 \%(\mathrm{w} / \mathrm{v})$ agarose gel prepared with Tris/Acetic acid/EDTA (TAE) buffer and stained with $5 \mu \mathrm{g} / \mathrm{ml}$ ethidium bromide and visualized under UV transillumination.

Nuclear extract preparation. For nuclear extraction, cells were harvested with a scraper in cold PBS, washed twice in the same buffer and resuspended in 5 volumes of fresh cold solution A (10 mM HEPES; pH 7.9, $10 \mathrm{mM} \mathrm{KCl,} 1.5 \mathrm{mM}$ $\mathrm{MgCl}_{2}, 0.1 \mathrm{mM}$ EGTA, $0.5 \mathrm{mM}$ DTT and $0.5 \mathrm{mM}$ PMSF). Resuspended cells were left on ice for $10 \mathrm{~min}$ and then centrifuged at $2000 \mathrm{rpm}$ for $10 \mathrm{~min}$ at $4^{\circ} \mathrm{C}$. The pellet was resuspended in 2 volumes of solution $\mathrm{A}$, and transferred to a Dounce homogenizer. Twenty strokes were applied with pestle $\mathrm{B}$. Then, 0.1 volume of restoring solution $(1 \mathrm{ml} 10 \mathrm{X}$ solution $\mathrm{A}$ and $9 \mathrm{ml}$ of $75 \%$ sucrose) was added and 4 more strokes were applied. The nuclear pellet was recovered by centrifugation at $10000 \mathrm{rpm}$ for $30 \mathrm{sec}$ at $4^{\circ} \mathrm{C}$. The supernatant (cytosolic fraction) was removed and the nuclear pellet was resuspended in 1 volume of nuclear resuspension buffer $(9 \mathrm{ml}$ solution $\mathrm{A}$ and $1 \mathrm{ml}$ restoring solution) and centrifuged at $10000 \mathrm{rpm}$ for $30 \mathrm{sec}$. The supernatant was removed and the nuclear pellet volume (NPV) was measured. The nuclear pellet was resupended in $5 \mathrm{NPV}$ of solution B $(10 \mathrm{mM}$ HEPES pH 7.9, $400 \mathrm{mM} \mathrm{NaCl}, 1.5 \mathrm{mM} \mathrm{MgCl}_{2}, 0.1 \mathrm{mM}$ EGTA, 0.5 mM DTT, $0.5 \mathrm{mM}$ PMSF and 5\% glycerol) and homogenized by applying 5 strokes with pestle B. The homogenate was transferred to a $15-\mathrm{ml}$ snug cap white test tube, shacked on ice for $30 \mathrm{~min}$, then centrifuged at $13000 \mathrm{rpm}$ for $30 \mathrm{~min}$ at $4^{\circ} \mathrm{C}$ to remove nuclear membranes. The supernatant containing the nuclear extract was used for Western blotting.

Western blotting. Nuclear protein extracts from cell lines were used for Western blot analysis. Antibody to B-catenin (Abcam, UK) was obtained commercially, and used as described previously (13). Equal protein loading was verified by Coumassie blue staining of the polyacrylamide gel.

\section{Results}

The implications of Wnt signaling in breast carcinogenesis are quite puzzling. On one hand, there is ample evidence for a direct role of aberrant Wnt signaling in mouse breast carcinogenesis. On the other hand, human breast cancer does not display mutations on $A P C, C T N N B 1$ and $A X I N 1$ genes that are known to be frequent mutational targets in other human cancers. In order to know whether and how the Wnt pathway genes play a role in human breast cancers, we performed a comprehensive analysis of major components of the Wnt signaling pathways in normal and malignant breast cell lines. Telomerase-immortalized human mammary epithelial cell line hTERT-HME1 (HMEC) was used as normal control. We also used a panel of six breast cancer cell lines that are commonly used for studies related to human breast cancer biology and genetics $(12,14-16)$.

Redundant expression of Frizzled receptors, LRP co-receptors and Lef/TCF transcription factors in human breast cancer cells. In mammals, Wnt signaling is mediated by ten different Frizzled (FZD) receptors. In addition, LRP5 and LRP6 coreceptors are involved in the canonical wnt/B-catenin signaling pathway. We first analyzed the expression of these receptors in normal and breast cancer cell lines by RT-PCR. Different Frizzled receptors have been implicated in canonical and noncanonical Wnt signaling. Most Frizzled genes lack intronic sequences. Therefore, we used primers derived from single exons for these studies. In order to avoid false positives due to genomic DNA interference, we included reverse transcriptasenegative controls for all studies. This allowed us to demonstrate the specificity of our RT-PCR experiments for gene expression. However, some non-specific bands were unavoidable for FZD1, FZD4, FZD5, FZD7 and FZD8 in some cell lines. For these cases, we compared the differences in PCR band intensities. With these precautions in mind, we detected strong expression of canonical receptors, FZD1, FZD7, FZD8 $(17,18)$, and non-canonical receptors, FZD3, FZD4, FZD6 (18-20), in HMEC cells. The non-canonical receptors, FZD2 (18) and FZD5 $(18,21)$, were weakly expressed. In contrast, 
Table I. List of primers.

\begin{tabular}{|c|c|c|c|c|c|c|}
\hline \multirow{2}{*}{$\frac{\text { Genes }}{\text { WNT1 }}$} & \multicolumn{2}{|c|}{ Primer sequence (forward - reverse) } & \multirow{2}{*}{$\frac{\mathrm{Mg}}{2}$} & \multirow{2}{*}{$\frac{\mathrm{Tm}}{57}$} & \multirow{2}{*}{$\frac{\text { Cycle }}{35}$} & \multirow{2}{*}{$\frac{\text { Size (bp) }}{469}$} \\
\hline & CAGTGGAAGGTGCAGTTGCAGC & CAGTGGAAGGTGCAGTTGCAGC & & & & \\
\hline WNT2 & CGGGAATCTGCCTTTGTTTA & ТССТTТССТTТССТТТССТT & 1.5 & 57 & 30 & 227 \\
\hline WNT2B & AAGATGGTGCCAACTTCACC & ATTTCTGCATTCCTTGCACC & 1.5 & 55 & 35 & 281 \\
\hline WNT3 & TCGGCGTGTTAGTGTCCAGG & CTTGTGCCAAAGGAACCCGTC & 1.5 & 60 & 35 & 396 \\
\hline WNT3A & GCACCACCGTCCACGACAGC & CCTCGCTACAGCCACCCCAC & 1.5 & 57 & 35 & 210 \\
\hline WNT4 & CCTTCGTGTACGCCATCTCT & TCAGAGCATCCTGACCACTG & 1 & 52 & 35 & 142 \\
\hline WNT5A & TGGCTTTGGCCATATTTTTC & CCGATGTACTGCATGTGGTC & 2 & 55 & 35 & 199 \\
\hline WNT5B & ACGCATCTGTCTTTGGGAGA & СССТGCTCCTCTGATCCTTT & 1 & 50 & 35 & 283 \\
\hline WNT6 & GGTTATGGACCCTACCAGCA & GGTTATGGACCCTACCAGCA & 1.5 & 58 & 35 & 250 \\
\hline WNT7A & CССАССТTCCTGAAGATCAA & ACAGCACATGAGGTCACAGC & 1.5 & 57 & 30 & 183 \\
\hline WNT7B & ATGCACAGAAACTTTCGCAA & TGCATCCGGTCCTCTAGAAC & 1.5 & 55 & 35 & 590 \\
\hline WNT8A & AACCTGTTTATGCTCTGGGC & GAAGAGCATTTTCAGGGCAG & 2 & 57 & 35 & 205 \\
\hline WNT8B & TTCCAAGCAGTTTGTCGATG- & GAGATGGAGCGAAAGGTGTC & 1.5 & 57 & 35 & 300 \\
\hline WNT9A & TGGAGGCCGTGAGCATGAGT & CTTAAGGTTGTCTCCGCAGC & 1 & 58 & 35 & 272 \\
\hline WNT9B & TGCACCTGTGATGACTCTCC & CTGATACGCCATGGCACTTA & 1 & 53 & 35 & 223 \\
\hline WNT10A & TCTTCCTACTGCTGCTGGCT & TAGGGGATCTTGTTGCGAGT & 1 & 53 & 35 & 274 \\
\hline WNT10B & CATCCAGGCACGAATGCCAATC & AGGCTCCAGAATTGCGGTTGTG & 2 & 60 & 35 & 217 \\
\hline WNT11 & GTGTGCTATGGCATCAAGTG & AGCTCAATGGAGGAGCAGTT & 1 & 53 & 35 & 227 \\
\hline WNT16 & CCAAGGAAACTGGATGTGGT & TCATGCAGTTCCATCTCTCG & 3 & 54 & 35 & 200 \\
\hline FZD1 & TCAACTACCACTTCCTGGGG & CAGCACAGCACTGACCAAAT & 2 & 52 & 35 & 136 \\
\hline FZD2 & CTTCTGGGCCACACGAACCAG & GGCACCCGGCTGCAGTCCCGG & 1.5 & 55 & 35 & 350 \\
\hline FZD3 & GTATGGAATATGGACGTGTCACAC & TATGAGATCCTTGTGTCACTGTGG & 2.5 & 55 & 35 & 581 \\
\hline FZD4 & GCCAATGTGCACAGAGAAGA & GGTTTTGTGAGGTAAGGGCA & 1.5 & 52 & 35 & 211 \\
\hline FZD5 & TTCTGGATAGGCCTGTGGTC & AGGTAGCAGGCTGACAGGAA & 2 & 52 & 35 & 128 \\
\hline FZD6 & CAAATTCATGTGGTTCCACCT & TGCCTTGGACACCAAAATCCA & 1.5 & 52 & 35 & 229 \\
\hline FZD7 & CCAACGGCCTGATGTACTTT & GAGAACGGTAAAGAGCGTCG & 2 & 50 & 35 & 104 \\
\hline FZD8 & AAGACAGGCCAGATCGCTAA & GACACGAAGAGGTAGCAGGC & 2 & 55 & 35 & 215 \\
\hline FZD9 & TGCCCCTCTCTGGCTACCTG & GGGCACCGTGTAGAGGATGG & 1.5 & 50 & 35 & 164 \\
\hline FZD10 & CCTCCAAGACTCTGCAGTCC & CTCCAAGACTCTGCAGTCC & 1.5 & 50 & 35 & 160 \\
\hline LRP5 & AAACAGCAGTGCGACTCCTTC & TGGCACACAAAATAGACACCA & 2 & 55 & 35 & 170 \\
\hline LRP6 & TCAAGCACCAAAGGCACTTAC & CTTGGCTGTTGCCACTGA & 2 & 52 & 35 & 242 \\
\hline LEF1 & TCAGGTACAGGTCCAAGAATGA & AAGAGGGGTTGGCAGTGATT & 1.5 & 55 & 35 & 245 \\
\hline TCF1 & TGGCTTCTACTCCCTGACCT & TCTCTGCCTTCCACTCTGCT & 1.5 & 57 & 35 & 206 \\
\hline TCF3 & TCGAGAAGAACAGGCCAAGT & GGGGCAGGCTGAACACATTA & 1.5 & 55 & 35 & 218 \\
\hline TCF4 & TGTACCCAATCACGACAGGA & GCCAGCTCGTAGTATTTCGC & 1.5 & 60 & 35 & 406 \\
\hline
\end{tabular}

we were not able to detect the expression of FZD9 and FZD10 in HMEC cells (Fig. 1). In breast cancer cell lines, the overall expression pattern of Frizzled receptors did not show any striking change. The receptors, FZD1, FZD2, FZD4 and $F Z D 6$, were equally well expressed in all six breast cancer cell lines. Strong expression of FZD3, FZD5, FZD7, FZD8 and $F Z D 9$ genes was observed in a subset of these malignant cell lines. We were unable to detect FZD10 in breast cancer cell lines, as was the case with HMEC. The LRP5 and LRP6 co-receptors involved in the canonical Wnt signaling pathway were also expressed in all cell lines (Fig. 1).

Transcriptional regulation by canonical Wnt signaling is mediated by $ß$-catenin, which forms active complexes with the family of four Lef/TCF transcription factors $(1,2)$. Our results showed strong expression of TCF1 (TCF7), and moderate expression of $L E F 1$, TCF3 (TCF7L1) and TCF4 (TCF7L2) in HMEC cells. Redundant expression of TCF1, TCF3 and TCF4 was observed in most of the cancer cell lines that were tested. The LEF1 gene, on the other hand, displayed strong expression in only three of the six cell lines (Fig. 1).

Collectively, these observations indicated that both normal and malignant breast epithelial cells express all major cell surface and intracellular components of the Wnt signaling pathway.

Redundant expression of canonical Wnt ligands in breast cancer cells. Experimental data from different animal models indicate that the Wnt pathway generates different signals mediated by so-called canonical and non-canonical signaling 


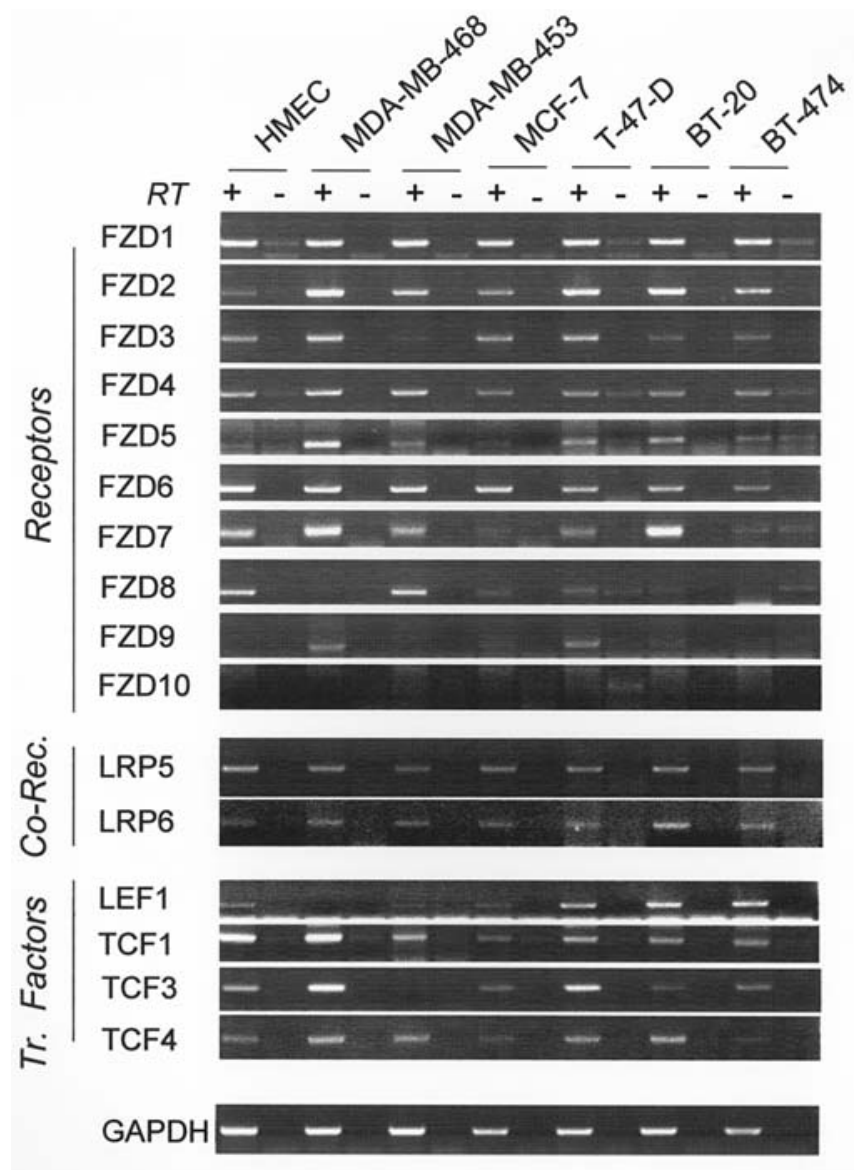

Figure 1. Expression profile analysis of Frizzled receptors, co-receptors and Lef/TCF transcription factors in immortalized mammary epithelial (HMEC) and breast cancer cell lines. Total RNA from each cell line was reverse transcribed and amplified with primers specific for each indicated gene. PCR conditions and cycle number were indicated in Table I. PCR products were resolved on a $2 \%$ agarose gel and visualized by ethidium bromide staining. For all cell lines, RT negative control without reverse transcriptase (-) was used in parallel with cDNA (+). GAPDH is used as an internal control for equal cDNA amount. RT, reverse transcriptase.

systems. Although the exact mechanisms that differentiate between these signaling pathways are not well defined, Wnt ligands appear to play a major role in defining the cellular choices between canonical and non-canonical pathways, probably by interacting with selective subsets of Frizzled receptors (17-23). Therefore, we next compared the expression pattern of all Wnt ligands in HMEC with that of breast cancer cell lines. Normal HMEC cells expressed WNT1, WNT2B, WNT3, WNT5A, WNT5B, WNT7B and WNT16 strongly. They also expressed $W N T 9 A$ and $W N T 10 B$ weakly. The expression of WNT10A was scarce. On the other hand, HMEC cells did not express WNT2, WNT3A, WNT4, WNT6, WNT7A, WNT8A, WNT8B, WNT9B or WNT11, significantly (Fig. 2). When compared with HMEC, the expression of WNT4, WNT9A and WNT10B was strongly up-regulated in all cancer cell lines tested. WN8B expression was also upregulated in all cell lines. In addition, the expression of WNT3A and WNT6 was also up-regulated, but in a subset of cell lines. In contrast, the expression of WNT5A, WNT5B and WNT16 was either decreased or lost in breast cancer cell lines. There was no major change in the expression of other

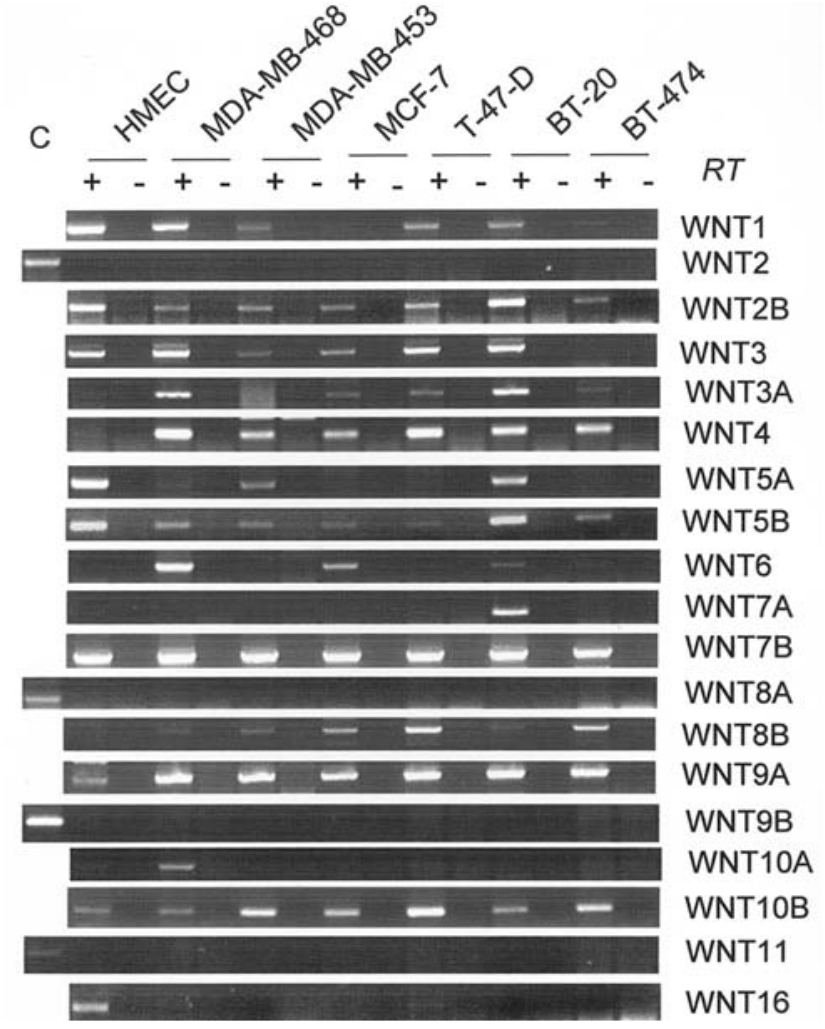

Figure 2. Expression profile analysis Wnt ligands in immortalized mammary epithelial (HMEC) and breast cancer cell lines. Total RNA from each cell line was reverse transcribed and amplified with specific primers for each indicated Wnt gene. PCR conditions and cycle number were indicated in Table I. PCR products were resolved on a $2 \%$ agarose gel and visualized by ethidium bromide staining. For all cell lines, RT negative control without reverse transcriptase (-) was used in parallel with cDNA (+). GAPDH is used as an internal control for equal cDNA amount. RT, reverse transcriptase.

Wnt ligands, including WNT1, WNT2, WNT3, WNT7A, WNT8A, WNT9B, WNT10A and WNT11 (Fig. 2).

Table II highlights major Wnt expression changes in breast cancer cell lines, in comparison with HMEC cells. Wnt genes whose expression was either up-regulated or maintained in breast cancer cell lines (WNT3A, WNT4, WNT6, WNT7B, WNT8B, WNT9A, WNT10B) form group I ligands. Among these ligands, WNT8B, WNT3A, WNT6, WNT9A and WNT10B activate only canonical wnt/B-catenin signaling. The remaining two (WNT4 and WNT7B) are known to activate both canonical and non-canonical Wnt signaling, depending on the cellular context. Furthermore, WNT4, WNT7B, WNT8B and WNT10B are known to display transforming activity in mammary epithelial cells in vivo or in vitro (see Table II for references). Three Wnt ligands, namely WNT5A, WNT5B and WNT16 form group II ligands that display down-regulation of expression in most or all breast cancer cell lines. It is noteworthy that two of these three ligands, WNT5A and WNT5B, are known to activate non-canonical wnt signaling, WNT16 being ill-known. Furthermore, WNT5A has been defined as a tumor suppressor in other malignancies $(24,25)$ as well as an inhibitor of canonical Wnt/B-catenin signaling (24-28). Collectively, these observations indicate that Wnt ligand expression in human breast cancer cell lines is dominated by canonical Wnt ligands. The alteration within the types of Wnt ligand expression 
Table II. Up-regulation of canonical Wnt and down-regulation of non-canonical Wnt ligands in breast cancer cell lines.

\begin{tabular}{|c|c|c|c|c|c|}
\hline \multirow[b]{2}{*}{ Wnt ligand } & \multirow{2}{*}{$\begin{array}{l}\text { Expression in breast } \\
\text { cancer cell lines }\end{array}$} & \multicolumn{2}{|c|}{ Transforming activity } & \multirow[b]{2}{*}{ Signaling pathways } & \multirow[b]{2}{*}{ Refs. } \\
\hline & & in vitro & in vivo & & \\
\hline \multicolumn{6}{|c|}{$\begin{array}{l}\text { Group I: expressed } \\
\text { and up-regulated }\end{array}$} \\
\hline WNT4 & Strongly up-regulated & No & Yes & Canonical and non-canonical & $(22,23,35-37)$ \\
\hline WNT9A & Strongly up-regulated & ND & No data & Canonical & $(38)$ \\
\hline WNT10B & Strongly up-regulated & ND & Oncogene & Canonical & $(33,34,39,40)$ \\
\hline WNT8B & Up-regulated & Yes & No data & Canonical & (39) \\
\hline WNT3A & Partially up-regulated & Yes & No data & Canonical & $(23,39)$ \\
\hline WNT6 & Partially up-regulated & Yes/no & No data & Canonical & $(22,23,41)$ \\
\hline WNT7B & Maintained & Yes/no & No & Canonical and non-canonical & $(22,23,35,39,42,43)$ \\
\hline \multicolumn{6}{|c|}{$\begin{array}{l}\text { Group II: } \\
\text { down-regulated }\end{array}$} \\
\hline WNT5A & Decreased & No & No data & Non-canonical & $(21-23,25,27,28,44)$ \\
\hline WNT5B & Decreased/lost & Yes/no & No & Non-canonical & $(22,23,44,45)$ \\
\hline WNT16 & Lost & ND & No data & No data & $(46)$ \\
\hline
\end{tabular}

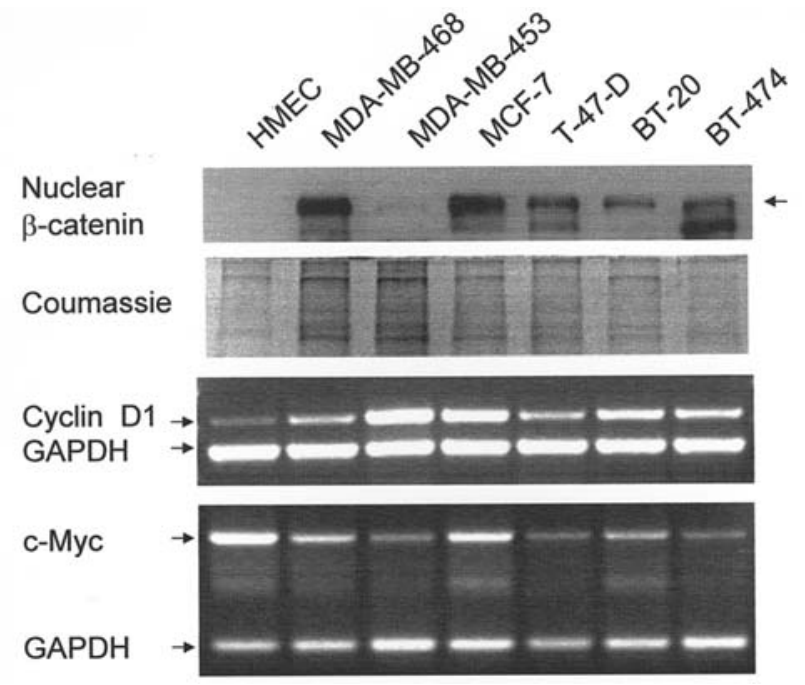

Figure 3. Nuclear accumulation of $\beta$-catenin protein and induction of cyclin D1 transcripts in breast cancer cell lines. Nuclear protein fractions from HMEC and breast cancer cell lines were subjected to 10\% PAGE and probed with a monoclonal anti-ß-catenin antibody. Loading control was made by Coumassie blue staining of total nuclear proteins. Middle and bottom panel shows multiplex RT-PCR analysis of cyclin D1 or c-myc together with GAPDH as an internal control.

strongly suggests a ligand-dependent activation of canonical wnt/ß-catenin signaling in human breast cancer.

Up-regulation of canonical Wnt ligands in breast cancer cells correlates with nuclear $\beta$-catenin accumulation and cyclin D1 up-regulation. Nuclear accumulation of B-catenin has been reported to be a good indication for canonical Wnt signaling activity $(1,2)$. Therefore, we next characterized the status of B-catenin protein and two major targets of the canonical Wnt signaling in breast cancer cell lines in comparison with HMEC cells. As shown in Fig. 3, no nuclear ß-catenin was detected in
HMEC cells. In contrast, all breast cancer cell lines displayed nuclear accumulation of $\beta$-catenin, which suggests canonical Wnt signaling activation. This pathway, when activated, leads to the up-regulation of cyclin D1 and c-myc transcripts in colorectal cancer $(29,30)$. Therefore, we also analyzed the transcript levels of these two target genes, using RT-PCR. Our results showed that the expression of cyclin D1 was weak in HMEC but was up-regulated in all tested breast cancer cell lines. We observed a correlation between the up-regulation of cyclin D1 and nuclear accumulation status of $\beta$-catenin, although cyclin D1 induction was not proportionally related to nuclear $\beta$-catenin levels. In contrast to cyclin D1, c-myc transcript levels were high in HMEC and did not correlate with nuclear ß-catenin accumulation.

\section{Discussion}

Our studies provide several new findings on the role of the Wnt pathway in human breast cancer cells. Firstly, a large set of ligands, receptors and transcription factors of the Wnt signaling pathway is expressed in human mammary epithelial cells. This strongly suggests that both canonical and noncanonical Wnt signaling pathways operate in adult mammary epithelial cells. Secondly, malignant transformation of breast epithelial cells in humans is associated with subtle changes in the expression profiles of Wnt signaling components. The most striking change is the up-regulation of the canonical Wnt ligands together with a decrease in non-canonical Wnt ligands. A previously published report indicated the expression of WNT3, WNT4 and WNT7B, but not WNT3A and WNT7A in human breast cancer cell lines (14). Our study not only confirmed these observations but also provided evidence that $W N T 9 A, W N T 10 B$ and $W N T 8 B$ were also up-regulated in all breast cancer cell lines studied. Previous reports indicating $W N T 8 B$ as a target of estrogen signaling in MCF-7 cells (31), and $W N T 1 O B$ as a known breast oncogene (32) and its role in 
the development of mammary adenocarcinomas in mice (33) increase the importance of our results. Other Wnt ligands, WNT6, WNT7A and WNT10A, were also overexpressed, but only in a few breast cancer cell lines. It is noteworthy that all Wnt ligands that are expressed or overexpressed in breast cancer cell lines are able to trigger canonical Wnt signaling (see Table II and references therein). Several other Wnt ligands, including WNT5A, WNT5B and WNT16, were expressed in HMEC but down-regulated in breast cancer cell lines. WNT5A and WNT5B are known to signal for the non-canonical pathway (see Table II and references therein). It therefore appears that, despite the redundant expression of many Wnt ligands in both non-malignant and malignant breast epithelial cell lines, breast cancer malignancy is associated with an overall up-regulation of canonical Wnt/ß-catenin signaling.

Canonical Wnt/B-catenin signaling plays a major role in cytoplasmic and/or nuclear accumulation of $B$-catenin $(2,5,6,12,34)$. Accumulation of $B$-catenin protein with induction of cyclin D1 expression is known to be a marker of poor prognosis in breast cancer (12). In line with these observations, we provide evidence for the nuclear accumulation of ß-catenin in breast cancer cell lines. In contrast, HMEC did not display any nuclear accumulation. It is known that breast cancer cells do not display mutations in known genes of the canonical Wnt- $\beta$-catenin signaling $(6,8-11)$. Therefore, nuclear $\beta$-catenin expression in breast cancer cells probably results from the autocrine activation of canonical signaling through the help of Wnt ligands that we have shown to be overexpressed in malignant cells. As shown in Fig. 3, there are differential nuclear $B$-catenin levels amongst the breast cancer cell lines that we tested. This difference may be an indication that the autocrine Wnt signaling in these cells occurs at variable intensities due to the heterogeneous expression of canonical and non-canonical Wnt ligands. An autocrine Wnt signaling mechanism has recently been proposed for breast cancer (15) and our results support this contention. We also noticed that, nuclear B-catenin accumulation shows a moderate correlation with cyclin D1 transcript levels in HMEC and breast cancer cell lines, whereas c-myc, another known target of canonical wnt- $\beta$-catenin signaling, appears to act independently (Fig. 3).

In conclusion, we propose that redundant expression of several canonical Wnt ligands is involved in the activation of canonical wnt/ß-catenin signaling, nuclear accumulation of B-catenin and induction of cyclin D1 overexpression in human breast cancer cell lines. This ligand-dependent and probably autocrine mechanism may provide an explanation for the lack of mutations in genes located downstream of Wnt-mediated Frizzled activation in human mammary cancer, despite the demonstrated role of Wnt genes in mouse breast cancer. Wnt ligands and Frizzled receptors that are overexpressed in breast cancer cells may serve as critical targets for the development of novel target-driven therapeutic applications for mammary tumors.

\section{Acknowledgments}

This work was supported by a grant from TUBITAK. Additional support was provided by Bilkent University and Turkish Academy of Sciences (TUBA).

\section{References}

1. Nusse R: Wnt signaling in disease and in development. Cell Res 15: 28-32, 2005

2. Kikuchi A: Regulation of beta-catenin signaling in the Wnt pathway. Biochem Biophys Res Commun 268: 243-248, 2000.

3. Van Es JH, Barker N and Clevers H: You Wnt some, you lose some: oncogenes in the Wnt signaling pathway. Curr Opin Genet Dev 13: 28-33, 2003.

4. Veeman MT, Axelrod JD and Moon RT: A second canon. Functions and mechanisms of beta-catenin-independent Wnt signaling. Dev Cell 5: 367-377, 2003.

5. Lustig B and Behrens J: The Wnt signaling pathway and its role in tumor development. J Cancer Res Clin Oncol 129: 199-221, 2003.

6. Giles RH, van Es JH and Clevers H: Caught up in a Wnt storm: Wnt signaling in cancer. Biochim Biophys Acta 1653: 1-24, 2003.

7. Cagatay T and Ozturk M: P53 mutation as a source of aberrant beta-catenin accumulation in cancer cells. Oncogene 21: 7971-7980, 2002.

8. Brown AM: Wnt signaling in breast cancer: have we come full circle? Breast Cancer Res 3: 351-355, 2001

9. Ueda M, Gemmill RM, West J, et al: Mutations of the beta- and gamma-catenin genes are uncommon in human lung, breast, kidney, cervical and ovarian carcinomas. Br J Cancer 85: 64-68, 2001.

10. Howe LR and Brown AM: Wnt signaling and breast cancer. Cancer Biol Ther 3: 36-41, 2004.

11. Brennan KR and Brown AM: Wnt proteins in mammary development and cancer. J Mammary Gland Biol Neoplasia 9: 119-131, 2004.

12. Lin SY, Xia W, Wang JC, et al: Beta-catenin, a novel prognostic marker for breast cancer: its roles in cyclin D1 expression and cancer progression. Proc Natl Acad Sci USA 97: 4262-4266, 2000.

13. Erdal E, Ozturk N, Cagatay T, Eksioglu-Demiralp E and Ozturk M: Lithium-mediated downregulation of PKB/Akt and cyclin E with growth inhibition in hepatocellular carcinoma cells. Int J Cancer 115: 903-910, 2005.

14. Huguet EL, McMahon JA, McMahon AP, Bicknell R and Harris AL: Differential expression of human Wnt genes 2, 3, 4, and 7B in human breast cell lines and normal and disease states of human breast tissue. Cancer Res 54: 2615-2621, 1994.

15. Bafico A, Liu G, Goldin L, Harris V and Aaronson SA: An autocrine mechanism for constitutive Wnt pathway activation in human cancer cells. Cancer Cell 6: 497-506, 2004.

16. Van de Wetering M, Barker N, Harkes IC, et al: Mutant Ecadherin breast cancer cells do not display constitutive Wnt signaling. Cancer Res 61: 278-284, 2001.

17. Gazit A, Yaniv A, Bafico A, Pramila T, Igarashi M, Kitajewski J and Aaronson SA: Human frizzled 1 interacts with transforming Wnts to transduce a TCF dependent transcriptional response. Oncogene 18: 5959-5966, 1999.

18. Umbhauer M, Djiane A, Goisset C, Penzo-Mendez A, Riou JF, Boucaut JC and Shi DL: The C-terminal cytoplasmic Lys-thr-X$\mathrm{X}-\mathrm{X}$-Trp motif in frizzled receptors mediates Wnt/beta-catenin signaling. EMBO J 19: 4944-4954, 2000.

19. Holmen SL, Salic A, Zylstra CR, Kirschner MW and Williams BO: A novel set of Wnt-Frizzled fusion proteins identifies receptor components that activate beta-catenindependent signaling. J Biol Chem 277: 34727-34735, 2002.

20. Golan T, Yaniv A, Bafico A, Liu G and Gazit A: The human Frizzled 6 (HFz6) acts as a negative regulator of the canonical Wnt. Beta-catenin signaling cascade. J Biol Chem 279: 14879-14888, 2004.

21. Weeraratna AT, Jiang Y, Hostetter G, Rosenblatt K, Duray P, Bittner $\mathrm{M}$ and Trent JM: Wnt5a signaling directly affects cell motility and invasion of metastatic melanoma. Cancer Cell 1: 279-288, 2002.

22. Shimizu H, Julius MA, Giarre M, Zheng Z, Brown AM and Kitajewski J: Transformation by Wnt family proteins correlates with regulation of beta-catenin. Cell Growth Differ 8: 1349-1358, 1997.

23. Wong GT, Gavin BJ and McMahon AP: Differential transformation of mammary epithelial cells by Wnt genes. Mol Cell Biol 14: 6278-6286, 1994.

24. Liang H, Chen Q, Coles AH, et al: Wnt5a inhibits B cell proliferation and functions as a tumor suppressor in hematopoietic tissue. Cancer Cell 4: 349-360, 2003. 
25. Kremenevskaja N, von Wasielewski R, Rao AS, Schofl C, Andersson T and Brabant G: Wnt-5a has tumor suppressor activity in thyroid carcinoma. Oncogene 24: 2144-2154, 2005.

26. Smit L, Baas A, Kuipers J, Korswagen H, van de Wetering M and Clevers H: Wnt activates the Tak1/Nemo-like kinase pathway. J Biol Chem 279: 17232-17240, 2004.

27. Topol L, Jiang X, Choi H, Garrett-Beal L, Carolan PJ and Yang Y: Wnt-5a inhibits the canonical Wnt pathway by promoting GSK-3-independent beta-catenin degradation. J Cell Biol 162: 899-908, 2003.

28. Ishitani T, Kishida S, Hyodo-Miura J, et al: The TAK1-NLK mitogen-activated protein kinase cascade functions in the Wnt$5 \mathrm{a} / \mathrm{Ca}(2+)$ pathway to antagonize Wnt/beta-catenin signaling. Mol Cell Biol 23: 131-139, 2003.

29. Tetsu O and McCormick F: Beta-catenin regulates expression of cyclin D1 in colon carcinoma cells. Nature 398: 422-426, 1999.

30. He TC, Sparks AB, Rago C, et al: Identification of c-MYC as a target of the APC pathway. Science 281: 1509-1512, 1998.

31. Saitoh T, Mine T and Katoh M: Expression and regulation of WNT8A and WNT8B mRNAs in human tumor cell lines: upregulation of WNT8B mRNA by beta-estradiol in MCF-7 cells, and down-regulation of WNT8A and WNT8B mRNAs by retinoic acid in NT2 cells. Int J Oncol 20: 999-1003, 2002.

32. Lee FS, Lane TF, Kuo A, Shackleford GM and Leder P: Insertional mutagenesis identifies a member of the Wnt gene family as a candidate oncogene in the mammary epithelium of int-2/Fgf-3 transgenic mice. Proc Natl Acad Sci USA 92: 2268-2272, 1995.

33. Lane TF and Leder P: Wnt-10b directs hypermorphic development and transformation in mammary glands of male and female mice. Oncogene 15: 2133-2144, 1997.

34. Chu EY, Hens J, Andl T, et al: Canonical WNT signaling promotes mammary placode development and is essential for initiation of mammary gland morphogenesis. Development 131: 4819-4829, 2004

35. Naylor S, Smalley MJ, Robertson D, Gusterson BA, Edwards PA and Dale TC: Retroviral expression of Wnt-1 and Wnt-7b produces different effects in mouse mammary epithelium. J Cell Sci 113: 2129-2138, 2000.
36. Lyons JP, Mueller UW, Ji H, et al: Wnt-4 activates the canonical beta-catenin-mediated Wnt pathway and binds Frizzled-6 CRD: functional implications of Wnt/beta-catenin activity in kidney epithelial cells. Exp Cell Res 298: 369-387, 2004.

37. Maurus D, Heligon C, Burger-Schwarzler A, Brandli AW and Kuhl M: Non-canonical Wnt-4 signaling and EAF2 are required for eye development in Xenopus laevis. EMBO J 24: 1181-1191, 2005.

38. Person AD, Garriock RJ, Krieg PA, Runyan RB and Klewer SE: Frzb modulates Wnt-9a-mediated beta-catenin signaling during avian atrioventricular cardiac cushion development. Dev Biol 278: 35-48, 2005.

39. Katoh M: Comparative genomics on Wnt8a and Wnt8b genes. Int J Oncol 26: 1129-1133, 2005

40. Miyoshi K, Rosner A, Nozawa M, et al: Activation of different $\mathrm{Wnt} /$ beta-catenin signaling components in mammary epithelium induces transdifferentiation and the formation of pilar tumors. Oncogene 21: 5548-5556, 2002.

41. Itaranta P, Lin Y, Perasaari J, Roel G, Destree O and Vainio S: Wnt-6 is expressed in the ureter bud and induces kidney tubule development in vitro. Genesis 32: 259-268, 2002.

42. Li X, Zhang Y, Kang H, et al: Sclerostin binds to LRP5/6 and antagonizes canonical Wnt signaling. J Biol Chem 280: 19883-19887, 2005.

43. Rosso SB, Sussman D, Wynshaw-Boris A and Salinas PC: Wnt signaling through Dishevelled, Rac and JNK regulates dendritic development. Nat Neurosci 8: 34-42, 2005.

44. Hartmann C: Wnt-signaling and skeletogenesis. J Musculoskelet Neuronal Interact 2: 274-276, 2002.

45. Kanazawa A, Tsukada S, Kamiyama M, Yanagimoto T, Nakajima $\mathrm{M}$ and Maeda S: Wnt5b partially inhibits canonical Wnt/beta-catenin signaling pathway and promotes adipogenesis in 3T3-L1 preadipocytes. Biochem Biophys Res Commun 330: 505-510, 2005.

46. McWhirter JR, Neuteboom ST, Wancewicz EV, Monia BP, Downing JR and Murre C: Oncogenic homeodomain transcription factor E2A-Pbx1 activates a novel WNT gene in pre-B acute lymphoblastoid leukemia. Proc Natl Acad Sci USA 96: 11464-11469, 1999. 